\title{
Foeniculum vulgare (Fennel) Effects on Puberty Timing, Reproductive Function and Behaviour in Adult Female Mice Following Neonatal Exposure
}

\author{
Rahmatollah Parandin ${ }^{1 *(D)}$, Namdar Yousofvand 2 (iD \\ 1. Dept. of Biology, Faculty of Sciences, Payame Noor University, Iran \\ 2. Dept. of Biology, Faculty of Sciences, Razi University, Kermanshah, Iran
}

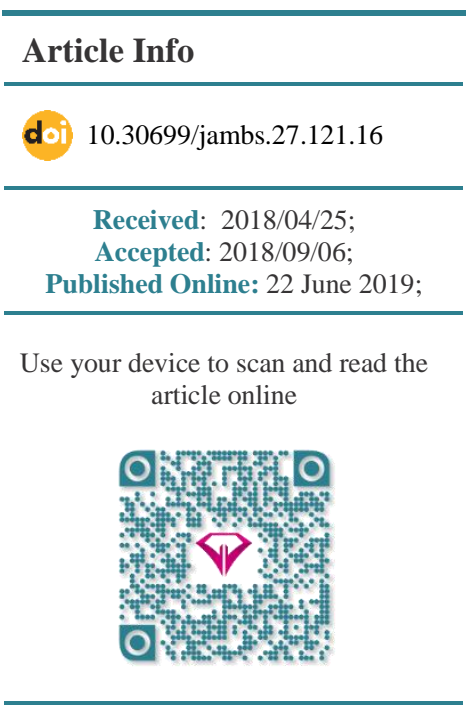

Corresponding Information: Rahmatollah Parandin, Dept. of Biology, Faculty of Sciences, Payame Noor University, Iran

Email: rahmatparandin@pnu.ac.ir

\begin{abstract}
Background \& Objective: Fennel, as an edible plant, and due to its estrogenic compounds, has widely been used as a therapeutic agent for centuries. In this study, the effects of neonatal exposure to fennel alcoholic extract (FAE), on the onset of puberty, estrus cycle, ovaries, and lordosis were investigated.
\end{abstract}

Materials \& Methods: In this experimental study, 48 female BALB/c pups were divided into 4 groups: control (without treatment), treatment with estradiol benzoate (EB), 100 and $200(\mathrm{mg} / \mathrm{kg}$ bw) FAE that were daily administered for 5 days from birth.

Results: The age at vaginal opening (VO) was significantly earlier in EB and 200 FAE. Body weight at VO was lower than control only in EB. A disrupted estrus cycle decreased number of cycles and increased index diestrus were observed in EB and 200 FAE treated mice. Ovary weight in the EB-, 100- and 200 FAE-treated groups were lower. The number of Graafian follicles in the EB-, 100- and 200 FAE and number of corpus luteum in the EB and $200 \mathrm{FAE}$ groups were lower than that of control females. Estradiol concentration increased in the EB and 200 FAE and LH concentration decreased in the EB-, 100- and 200 FAE groups. The lordosis quotient (LQ) was significantly low in the EB- and 200 FAE-treated groups, vis-à-vis the control group.

Conclusion: The present results indicated that neonatal exposure to FAE induces early VO and disrupts ovary function. In addition, fennel acts like xenoestrogens and causes defeminization of the brain in the estrus cycle as well as lordosis in mice.

Keywords: Foeniculumvulgare, Puberty, Reproductive Health, Lordosis

\section{Introduction}

Phytoestrogens are from plant sources with estrogenic activities, that are ubiquitous in both human and animal diets, and is structurally similar to the estradiol $\left(\mathrm{E}_{2}\right)$ hormone. These compounds exert their effects by binding to estrogen receptors (ERs) to stimulate or prevent estrogen signaling, though weaker than that of $E_{2}$. It is reported that almost all phytoestrogens consumed daily by people get into the sewer through urine and feces (1). Although several studies have confirmed that phytoestrogens yield favorable effects on human and animal safety, some study indicated that these herbal compounds also affected as endocrine disrupting chemicals (EDCs) $(\mathbf{1}, 2)$.

EDCs are external substances that alter the function of the endocrine glands and because different health disturbs by interfering with the synthesis, metabolism, binding or cellular signaling of endogenous estrogens (3). At the present time, the greatest unpleasant grasp regarding the unfavorable properties of EDCs, including phytoestrogens, concerns on their unfavorable effects on reproductive safety $(\mathbf{4 , 5})$. In recent years, studies have shown that concerns have been raised regarding the reproductive toxicity of dietary phytoestrogens (2). The research on phytoestrogens demonstrates that their effects on the female reproductive function depend on the age at which exposure occurred and the duration thereof. Neonatal exposure of some phytoestrogens such as genistein (6), coumestrol (7) or mycoestrogen zearalenone (8) resulted in severe alterations in the reproductive physiology of females. In neonatal rodent females, plasma $E_{2}$ level is relatively low owing to passive gonads and large amount of alpha-fetoprotein in circulation of a protein that potently attaches $\mathrm{E}_{2}$; low plasma $\mathrm{E}_{2}$ amount is an acute situation to the suitable formation of estrogen-sensitive reproductive organs and neurohormonal systems to govern the reproductive axis. In this hormonal critical period, development of reproductive system tissues and organs depends on the low amount of estrogen $(9,10)$. It is noteworthy that neither type of alpha-fetoprotein binds phytoestrogens (2).

Foeniculum vulgare (fennel) is a famous herb belonging to the Umbelliferae (Apiaceae) family, known and consumed around the world from ancient times. 
Fennel, as an estrogenic herb has been applied in medicinal uses for many cases of ailments related to reproductive (to increase libido and affect the menstrual cycle), endocrine, and digestive systems. In addition, this plant is also applied as an agent that increases the milk flow of mothers (11). Fennel has great potential in the fields of pharmacology and biomedicine as it has been reported to exhibit antibacterial, antifungal, antioxidant, antithrombotic, antidiabetic, cytoprotective, antitumour, acaricidal, anti-inflammatory, antihirsute cardiovascular, insecticidal, bronchodilatory and hepatoprotective activities (11-14). The main and most abundant component of fennel oil is trans-anethole that has been reported as an active estrogenic factor (13).

Despite the abundant literature about the benefits of fennel in humans and laboratory rodents (11-13), presently there is no knowledge about the estrogenic effects of fennel on reproductive system and its effect on females following neonatal exposure. Therefore, this study focused on the effects of neonatal exposure to fennel on the onset of puberty, on the estrus cycle, ovaries and on lordosis in adult female mice.

\section{Materials and Methods}

\section{Animals}

This research was approved by the ethics committee on animal studies, Payame Noor University (Protocol number: IR.PNU.REC.1396.1). In this experimental study, 3-month-old BALB/c pregnant mice were purchased from Razi institute of Karaj in Iran. The mice were housed in plastic cages under controlled conditions (12:12 h light/dark cycle, temperature of $22 \pm$ $1{ }^{\circ} \mathrm{C}$ and humidity of $55 \%+5 \%$ ) with voluntary access to water and chow.

\section{Preparation of Extract}

Fennel Seeds were purchased from the grocery store. The fennel alcoholic extract (FAE) was made based on the World Health Organization (WHO) guidance for provision of an alcoholic extract. Briefly, $100 \mathrm{~g}$ of dried seeds were powdered and added to $1000 \mathrm{ml}$ of $70 \%$ ethanol (v/v) and left to soak at $25^{\circ} \mathrm{C}$ for $20 \mathrm{~h}$. The basin was slowly rotated during this time. Following filtration, the alcohol was turn from liquid into vapor at low pressure at $30^{\circ} \mathrm{C}(14)$.

\section{Treatment}

After the neonates are born naturally, the birthday of the neonatal mice was determined as postnatal day (PND) 1 . 48 female neonates were randomly distributed into 4 groups $(n=12$, the 6 mice in each sub-group were used for the assessment of puberty onset, estrus cycle, graafian follicle (GF) count, corpus luteum (CL), levels of plasma hormones (the 6 mice in each sub-group used only for behavior testing) and were given one of the following neonatal injections $(0.05 \mathrm{~mL})$ in neck skinfold (subcutaneous method) during PND 1 to 5: 1: without treatment (control), 2: $10 \mu \mathrm{g} / \mathrm{kg}$ body weight (bw) estradiol benzoate as gold standard group (EB,
SigmaAldrich, Steinheim, Germany), 3 and 4: 100 and $200 \mathrm{mg} / \mathrm{kg}$ bw FAE (13). The neonates were weighed daily to inject a precise dose of drugs.

\section{Assessment of Puberty and Estrus Cycle}

The offspring were weaned on 21 days after birth and were checked daily for VO from 24 days after birth. Upon VO, the estrus cycle was assessed daily from 40 to 70 after birth. The presence of cornified cells as the sign of first estrus happens between 2-10 days after incidence of VO. For this purpose, the smears using a cotton tipped swab (with $0.9 \% \mathrm{NaCl}$ solution) were collected from vagina of mice in the morning. The smear was spotted on glass slides and dried in the air. Then microscopic slides were stained using methylene blue and observed with a light microscope. In the mice, the mean duration of the estrous cycle happens within between 4 to 5 days and it separated into 4 steps:

- The first step (proestrus) is the period during which conquest of nucleated epithelial cells become visible.

- The second step (estrus) is the period during which cornified squamous epithelial cells in clusters distinguished.

- The third step (metestrus), there is a mixture of all three cell types with a conquest of leukocytes, a few nucleated epithelial and/or cornified squamous epithelial cells.

- The fourth step (diestrus), this step contains mainly of

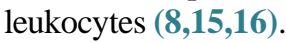

The diestrus index was assessed using the formula:

$$
\text { Diestrus index }=\frac{\text { Numbers of days with clear diestrus smear }}{\text { Total duration of treatment }(\text { Days })} \times 100
$$

\section{Collection of Tissue and Plasma}

In the diestrus step at PND 70, 6 mice were deeply anesthetized with ketamine and xylazine mixture. Then mice blood collected by cardiac puncture and was shed in EDTA-coated tubes. The plasma centrifuged at $2500 \mathrm{~g}$ for $15 \mathrm{~min}$ and kept at $-70^{\circ} \mathrm{C}$ until used in the assay. Ovaries were removed, weighted, and fixed in 10 percent formalin for 7 days at $4^{\circ} \mathrm{C}$.

\section{Count of Graafian Follicles and Corpus Luteum}

The ovaries were dehydrated by ethanol and embedded in paraffin. Serial sections were provided at thicknesses of $7 \mu \mathrm{m}$ and samples stained with H\&E stain. For each ovary, count of GF and CL was inquired with every $20^{\text {th }}$ histological section (8).

\section{Levels of Plasma Hormones}

Levels of hormones, including E2 and LH determined using commercially available radioimmunoassay (RIA) kits (Radim, Rome, Italy) according to the directions supplied by the manufacturer. 


\section{Behavioral Test (Lordosis)}

The behavioral test was directed in a glass aquarium (40 $\mathrm{cm}$ long, $30 \mathrm{~cm}$ high, $25 \mathrm{~cm}$ wide) whose floor was lidded with fresh sawdust. First, a sexually experienced vigorous male of the BALB/c mice was put alone in the glass and permitted to reconcile for $30 \mathrm{~min}$. Then a female was put in the glass and we registered the Lordosis behavior to the mounts of the stimulus male. The exam lasted until the female had received 10 mounts or $10 \mathrm{~min}$ had elapsed. The test was repeated at $9 \mathrm{pm}$ for three consecutive days. An LQ for each test was distinguished by dividing the number of times a female displayed lordosis by the whole number of mounts by the male sexual partner, and multiplying this value by $100(\mathbf{1 7 , 1 8})$.

\section{Data Analysis}

All assessments were analyzed using SPSS 19 (SPSS Inc., Chicago, Illinois, USA) and statistical analyses were performed by one-way analysis of variance (ANOVA). Then Tukey test used as post hoc test and data expressed as the mean \pm standard error of the mean (SEM). Pvalue $<0.05$ were considered significant.

\section{Results}

Neonatal treatment of FAE did not show any significant changes in body weight in mice as compared to control mice. Neonatal treatment of the EB group resulted in a significant decrease in body weight in comparison to the control group which denotes weight loss (igure 1).

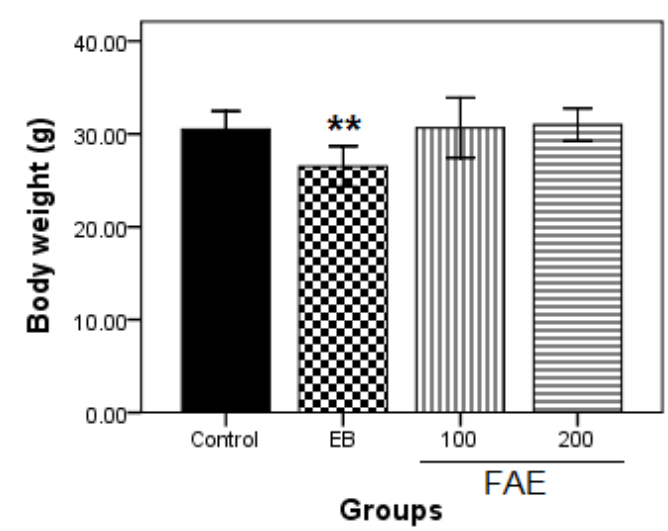

Figure 1. Body weight of female offspring on PND 70. Control: without treatment, EB: $10 \mathrm{mg} / \mathrm{kg}$, estradiol benzoate, FAE: 100 and $200 \mathrm{mg} / \mathrm{kg}$, fennel alcoholic extract. Data are the mean SEM. $* * P<0.01$ compared with control.

The age of VO was significantly advanced in the mice being treated with $10 \mu \mathrm{g} / \mathrm{kg}$ of $\mathrm{EB}(P<0.001)$ or $200 \mathrm{mg} / \mathrm{kg}$ of FAE $(P<0.05)$ than in the control group. However, the low dose $(100 \mathrm{mg} / \mathrm{kg})$ of FAE moderately, but not significantly, advanced the day of VO (Figure 2A). There was no difference in body weight at VO day among FAE-treated groups, and FAE treatment had no effect on either the growth or appearance of health among the mice. However body weight at VO day significantly $(P<0.01)$ decreased in the EB group's mice (Figure 2B).
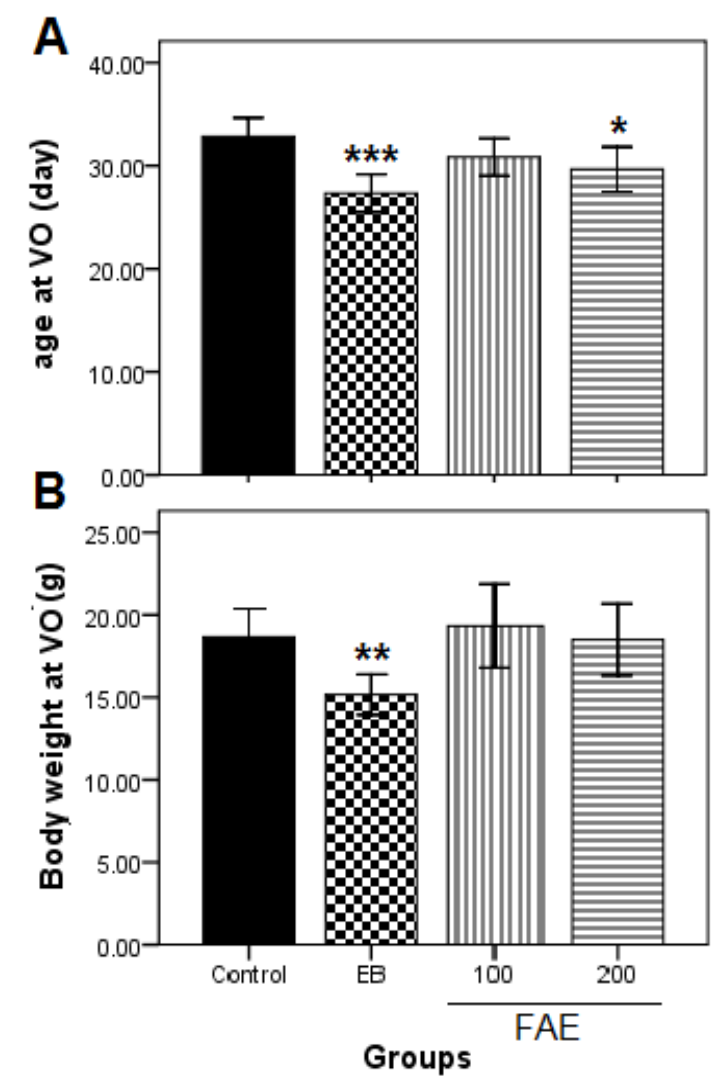

Figure 2. Age at VO (A) and body weight at VO (B) of female offspring. Control: without treatment, EB: 10 $\mathrm{mg} / \mathrm{kg}$, estradiol benzoate, FAE: 100 and $200 \mathrm{mg} / \mathrm{kg}$, fennel alcoholic extract. Data are the mean SEM. $* * * P<0.01$, $* * P<0.01$ and $* P<0.05$ compared with control.

The control group exhibited a regular estrus cycle and a normal duration for each stages of the estrus cycle for 30 days (Table 1). The estrus cycle was affected, showing a significant decrease in the number of estrus cycles $(P<0.001)$, in the duration of proestrus $(P<0.001)$, estrus $(P<0.01)$ and metestrus $(P<0.05)$, with a significant increase in the duration of diestrus $(P<0.001)$ and in the diestrus index $(P<0.001)$ in EBtreated mice. In addition, in FAE 200-treated mice, there was a significant decrease in the number of estrus cycles $(P<0.05)$, the duration of proestrus $(P<0.05)$, with a significant increase in the duration of the diestrus stage $(P<0.05)$ and the diestrus index $(P<0.05)$. However, treatment with FAE 100 has no significant effect on the number cycles, or the duration of each stage of the cycle, or the diestrus index when compared with the control group (Table 1).

In addition, the results in Table 1 showed a significant decrease of LQ for EB $(P<0.001)$ and FAE $200(P<0.01)$ groups compared with the control group. However, the low dose $(100 \mathrm{mg} / \mathrm{kg})$ of FAE moderately, but not significantly, decreased the rate of LQ. 
Table 1. Number of estrus cycles, duration of cycle stages, diestrus index and Lordosis quotient of offspring. Control: without treatment, EB: $10 \mathrm{mg} / \mathrm{kg}$, estradiol benzoate, FAE: 100 and $200 \mathrm{mg} / \mathrm{kg}$, fennel alcoholic extract.

\begin{tabular}{|c|c|c|c|c|c|c|c|}
\hline \multirow{2}{*}{ groups } & \multirow{2}{*}{$\begin{array}{c}\text { number of } \\
\text { cycles }\end{array}$} & \multicolumn{4}{|c|}{ duration in days } & \multirow{2}{*}{$\begin{array}{c}\text { diestrus } \\
\text { index }\end{array}$} & \multirow{2}{*}{ Lordosis quotient } \\
\hline & & proestrus & estrus & metestrus & diestrus & & \\
\hline Control & $5.33 \pm 0.21$ & $5.83 \pm 0.31$ & $7.83 \pm 0.31$ & $5.17 \pm 0.31$ & $11.17 \pm 0.79$ & $36.82 \pm 2.97$ & $78.33 \pm 4.77$ \\
\hline EB & $3.33 \pm 0.21 * * *$ & $3.67 \pm 0.33 * * *$ & $5.83 \pm 0.31 * *$ & $3.83 \pm 0.17 *$ & $16.67 \pm 0.67 * * *$ & $55.56 \pm 2.22 * * *$ & $21.67 \pm 7.49 * * *$ \\
\hline $\begin{array}{c}100 \\
\text { FAE }\end{array}$ & $5.00 \pm 0.36$ & $5.33 \pm 0.42$ & $7.33 \pm 0.33$ & $5.67 \pm 0.33$ & $11.67 \pm 0.92$ & $38.48 \pm 3.39$ & $63.33 \pm 2.12$ \\
\hline $\begin{array}{c}200 \\
\text { FAE }\end{array}$ & $4.17 \pm 0.31 *$ & $4.50 \pm 0.22 *$ & $6.67 \pm 0.42$ & $4.33 \pm 0.33$ & $14.50 \pm 0.81 *$ & $48.33 \pm 2.69 *$ & $50.00 \pm 5.77 * *$ \\
\hline
\end{tabular}

Data are the mean SEM. $* * * P<0.01, * * P<0.01$ and $* P<0.05$ compared with control.

Ovary/body weight significantly decreased in the mice being treated with EB $(P<0.001), 100(P<0.05)$ or 200 FAE $(P<0.01)$. The number of GF significantly decreased in the mice being treated with $\mathrm{EB}(P<0.001)$ or 200 FAE $(P<0.01)$ compared to the control mice. Additionally, the number of CL significantly decreased in the mice being treated with EB $(P<0.001), 100$ $(P<0.05)$ or 200 FAE $(P<0.001)$ compared to the control mice (Table 2). This data may be due to hormonal imbalance and decrease in the LH hormone. The results in Figure 3 showed a significant increase of the $\mathrm{E}_{2}$ hormone for $\mathrm{EB}(P<0.001)$ and FAE 200 $(P<0.05)$ groups and a significant decrease of $\mathrm{LH}$ hormone levels for EB $(P<0.001)$, FAE $100(P<0.05)$ and FAE $200(P<0.001)$ compared to the control group.

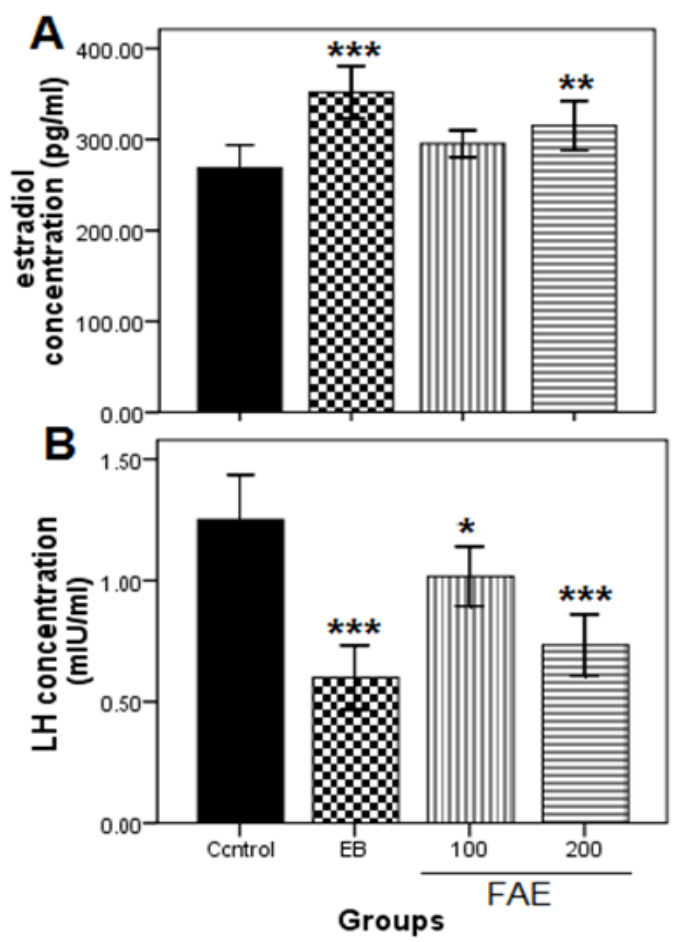

Figure 3. Estradiol (A) and LH (B) concentration of offspring on PND 70. Control: without treatment, EB: $10 \mathrm{mg} / \mathrm{kg}$, estradiol benzoate, FAE: 100 and $200 \mathrm{mg} / \mathrm{kg}$, fennel alcoholic extract. Data are the mean SEM. $* * * P<0.01$, $* * P<0.01$ and $* P<0.05$ compared with control.
Table 2. Ovary/body weight and number of graafian follicles and corpus luteum of offspring on PND 70. Control: without treatment, EB: $10 \mathrm{mg} / \mathrm{kg}$, estradiol benzoate, FAE: 100 and 200 $\mathrm{mg} / \mathrm{kg}$, fennel alcoholic extract.

\begin{tabular}{cccc} 
groups & $\begin{array}{c}\text { Ovary/Body } \\
\text { Weight }(\mathrm{mg})\end{array}$ & $\begin{array}{c}\text { Graafian } \\
\text { Follicles }\end{array}$ & $\begin{array}{c}\text { Corpus } \\
\text { Luteum }\end{array}$ \\
\hline Control & $0.047 \pm 0.002$ & $12.00 \pm 0.58$ & $35.33 \pm 1.80$ \\
EB & $0.035 \pm 0.002 * * *$ & $3.17 \pm 1.22 * * *$ & $12.33 \pm 1.74 * * *$ \\
100 & $0.039 \pm 0.001 *$ & $10.83 \pm 0.60$ & $27.67 \pm 1.74 *$ \\
FAE & & & \\
200 & $0.038 \pm 0.001 * *$ & $8.50 \pm 0.76 * *$ & $20.83 \pm 2.20 * * *$ \\
FAE & &
\end{tabular}

Data are the mean SEM. $* * * P<0.01, * * P<0.01$ and $* P<0.05$ compared with control. $(\mathrm{n}=6)$.

\section{Discussion}

The findings of the present study indicate that, similar to the EB group, neonatal treatment of FAE especially in higher dose $(200 \mathrm{mg} / \mathrm{kg})$ altered the reproductive function in the form of accelerated puberty onset, disrupted estrus cycles, altered estradiol and LH hormone levels, a decrease of ovary FG and CL and decrease of sexual behavior. This data suggests that neonatal FAE treatment may be responsible for defeminizing hypothalamic neural networks, controlling the female reproductive axis, therefore altering hormonal levels, and is subsequently responsible for the deficiency in reproductive function and sexual behavior.

Sex differentiation of the brain is governed by endogenous sex hormones, which are also key players of the neuroendocrine systems controlling puberty onset. Accordingly, both states might be sensitive to the disrupting actions of external substances with sex steroidlike activity that may pose long-lasting outcomes in terms of reproductive safety. It is obvious that the phenomenon of sex differentiation of the brain in laboratory rodents occur during critical periods of development, especially the neonatal period, when key neuronal systems at the hypothalamus become determined in a permanent 
procedure differentially in different genders. Evidence of rodents have indicated that the key molecular signal responsible for brain feminization is low estrogen input due to passive ovaries and high amounts of circulating $\alpha$ fetoprotein. According to the above functional aspects, it is acceptable that EDCs with sex hormone-like actions may effect at central levels to interfere with suitable sexual differentiation or later maturation of the reproductive system (4). Exposure to EDCs with sex steroid-like activities and phytoestrogens show that they may not have the ability to bind to alpha-fetoprotein and are therefore able to cross the blood-brain barrier and alter development of a normal female brain $(2,19,20)$.

In the present study, the $\mathrm{VO}$ age of FAE-treated mice was found to have accelerated and the estrus cycle was disrupted compared to the control group's mice. These results are consistent with the effects in previous studies on the neonatal administration of phytoestrogens genistein (6), coumestrol (7), mycoestrogen zearalenone (8), tamoxifen (21) and BPA (22) to laboratory rodents. $\mathrm{VO}$ is an apoptosis-mediated event used as an exogenous indicator of puberty onset. It happens as a result of increasing $\mathrm{E}_{2}$ secretion and can be motivated by treatment of $\mathrm{E}_{2}(\mathbf{1 6})$ and estrogenic EDCs $(6-8,21)$ into rodents. In this study, $\mathrm{E}_{2}$ levels also increased in FAE-treated mice. Puberty onset in many species involves reduced sensitivity of the hypothalamic nuclei controlling the reproductive axis to steroid negative feedback (23-25). In addition, minor changes of gonadal hormone level during the neonatal stage can accelerate development and growth of reproductive system (26).

In rodents, estrogen-sensitive brain nuclei, anteroventral periventricular (AVPV) nucleus and arcuate (ARC) nucleus impose Supervisory control over reproductive system physiology such as the timing of puberty onset and estrus cycle. Previous data from female rodents demonstrated that the lesions on these neuronal nuclei disorder the reproductive physiology $(8,21,27-29)$. These hypothalamic nuclei have been reported to be sexually dimorphic. These sexual differences in reproductive functions are formed by low $\mathrm{E}_{2}$ level in the neonatal stage in female rodents, because exposure to estrogen or phytoestrogens in neonatal female rodents caused a decrease in LH surge, a decrease in CL and disruption of the estrous cycle $(9,30,31)$. In agreement with this issue, here, LH levels also decreased in FAEtreated mice.

Similar to the EB group, ovary weight and the number of GF and CL were decreased significantly in the mice treated with FAE. This data may be due to hormonal imbalance and a decrease in the LH hormone. Similar findings have been expressed in rodents treated with genistein (6) and coumestrol (7). Weight and ovarian function are controlled by gonadotropins, which functions in a coordinated procedure with a specific mark provided by the ovary through the pituitary gland and is accountable for metabolism of gonadotropins. Gonadotropin hormones in turn perform an important role in the control of folliculogenesis. Accordingly, toxic substances that interfere with the ovarian physiology could do so indirectly by acting on sensitive brain areas (32).

Similar to the EB group, LQ was declined significantly in the mice administered with FAE. The Ventromedial Hypothalamic Nucleus (VMN) is an important site for female sexual response. Lesions on this hypothalamic area delete the lordosis behavior in female rats, and implanting E2 directly into the VMN induces the behavior. Neurons in the ventrolateral subdivision represent high levels of ER and project to the midbrain central gray, forming an essential link in the neural circuitry regulating female sex response. Defeminization is an $E_{2}$-mediated active process that either blocks the organization of the feminine network or somehow overrides it, resulting in a permanent prevention of female sex response (31). Such a difference in the impact of FAE on the behavior of Lordosis in female mice is in agreement with the findings of other studies about other phytoestrogens $(6,7)$.

It might be possible that during neonatal exposure, estrogenic components of fennel such as trans-anethole bind with ER in the hypothalamus, which has been found to decrease the construction of $\mathrm{GnRH}$, therefore decreasing the secretion of FSH and LH. The low level of FSH and LH may lead to decreased folliculogenesis and ovulation. The feedback blockage of GnRH secretion by estrogens provides the basis for the most widely used form of contraception. Such feedback blockage of GnRH inhibits the midcycle surge of LH and ovulation (33). Trans-anethole (anethole; 1-methoxy-4-(1E)-1propenylbenzene) is a benzene ring with a single methoxy group para to the double-bonded propenyl group, occurs naturally as a key constituent of the essential oils in fennel. The trans isomer is by far more abundant (>99\%) than the cis isomer in natural oils. Anethole is a major component of the essential oils obtained from fennel and anise, which are known to have estrogen-like activities as well as pharmacological properties in traditional medicines (34). Although many natural and synthetic compounds are found everywhere, little is obvious about harmful effects to humans while being exposed to known exogenous estrogens. As a result, remarkable consideration has focused on dietary phytoestrogens bearing hydroxyl groups as EDCs exhibiting weak estrogenic activity in in vivo and in vitro bioassays (34-37). However, further 
investigations on the mechanism of fennel and its estrogenic components including trans-anethole about this toxicity are necessary.

\section{Conclusion}

Overall, the results of this study demonstrated that alterations in the FAE-treated mice are like those observed after neonatal treatment of estradiol benzoate. As a result, this data demonstrated that FAE that was injected on days 1-5 may act as an agent with estrogenic function on the hypothalamic nuclei regulating reproductive physiology and behavior in female rodents.

\section{Acknowledgements}

Financial support of this study (grant, No. 68424) was performed by Payame Noor University, which is greatly appreciated.

\section{Conflict of Interest}

Authors declared no conflict of interests.

\section{References}

1. Liu ZH, Kanjo Y, Mizutani S. A review of phytoestrogens: their occurrence and fate in the environment. Water Res. 2010; 44(2): 567-77. [DOI:10.1016/j.watres.2009.03.025] [PMID]

2. Jefferson WN, Patisaul HB, Williams CJ. Reproductive consequences of evelopmental phytoestrogen exposure. Reproduction. 2012; 143(2): 247-60. [DOI:10.1530/REP-110369] [PMID] [PMCID]

3. Roy JR, Chakraborty S, Chakraborty TR. Estrogen-like endocrine disrupting chemicals affecting puberty in humans-a review. Med Sci Monit. 2009; 15(6): 137-45.

4. Tena-Sempere M. The Kisspeptin System as Putative Target for Endocrine Disruption of Puberty and Reproductive Health. In 'Multi-System Endocrine Disruption'. (Eds Bourguignon JP, Jegou B, Kerdelhue B, Toppari J, Christen Y). SpringerVerlag- Berlin. 2011; pp. 23-41. [DOI:10.1007/978-3-64222775-2_2]

5. Sifakis S, Androutsopoulos VP, Tsatsakis AM, Spandidos DA. Human exposure to endocrine disrupting chemicals: effects on the male and female reproductive systems. Environ Toxicol Pharmacol. 2017; 51: 56-70. [DOI:10.1016/j.etap.2017.02.024] [PMID]

6. Kouki T, Kishitake M, Okamoto M, Oosuka I, Takebe M, Yamanouchi K. Effects of neonatal treatment with phytoestrogens, genistein and daidzein, on sex difference in female rat brain function: estrous cycle and lordosis. Horm Behav. 2003; 44(2): 140-5. [DOI:10.1016/S0018506X(03)00122-3]

7. Kouki T, Okamoto M, Wada S, Kishitake M, Yamanouchi K. Suppressive effect of neonatal treatment with a phytoestrogen, coumestrol, on lordosis and estrous cycle in female rats. Brain Res Bull. 2005; 64(5): 449-54. [DOI:10.1016/j.brainresbull.2004.10.002] [PMID]

8. Parandin R, Behnam-Rassouli M, Mahdavi-Shahri N. Effects of neonatal exposure to zearalenone on puberty timing, hypothalamic nuclei of AVPV and ARC, and reproductive functions in female mice. Reprod Sci. 2005; 24(9): 1293-303. [DOI:10.1177/1933719116683808] [PMID]

9. Wilson CA, Davies DC. The control of sexual differentiation of the reproductive system and brain. Reproduction. 2007; 133(2): 331-59. [DOI:10.1530/REP-06-0078] [PMID]

10. Cao J, Patisaul HB. Sexually dimorphic expression of hypothalamic estrogen receptors $\alpha$ and $\beta$ and kiss 1 in neonatal male and female rats. J Comp Neurol. 2011; 19(15): 2954-77. [DOI:10.1002/cne.22648] [PMID] [PMCID]

11. Badgujar SB, Patel VV, Bandivdekar AH. Foeniculum vulgare Mill: a review of its botany, phytochemistry, pharmacology, contemporary application, and toxicology. Biomed Res Int. 2014; 2014: 842674. [DOI:10.1155/2014/842674] [PMID] [PMCID]

12. Albert-Puleo M. Fennel and anise as estrogenic agents. J Ethnopharmacol. 1980; 2(4): 334-44. [DOI:10.1016/S03788741(80)81015-4]

13. Rather MA, Dar BA, Sofi SN, Bhat BA, Qurishi MA. Foeniculum vulgare: A comprehensive review of its traditional use, phytochemistry, pharmacology, and safety. Arab J Chem. 2016; 9: 1574-83. [DOI:10.1016/j.arabjc.2012.04.011]

14. Khazaei M, Montaseri A, Khazaei MR, Khanahmadi M. Study of Foeniculum vulgare effect on folliculogenesis in female mice. Int J Fertil Steril. 2011; 5(3): 122-7.

15. Fox JG, Davisson MT, Quimby FW, Barthold SW, Newcomer CE, Smith AL. 'The mouse in biomedical research: Normative Biology, Husbandry, and Models.' 2nd edn. 2007; (Academic Press, New York.).

16. Caligioni CS. Assessing reproductive status/stages in mice. Curr Protoc Neurosci. 2009; Appendix 4: Appendix 4I. [DOI:10.1002/0471142301.nsa04is48] [PMCID]

17. Nwafor PA, Egwu G, Jahn GA, Deis RP. Effects of methanolic extract of Asparagus pubescens root on sexual behavior and pituitary hormone secretion on wistar rats during pregnancy and lactation. J Ethnopharmacol. 2007; 113(3): 492-7. [DOI:10.1016/j.jep.2007.07.002] [PMID]

18. Avitsur R, Yirmiya R. The partner preference paradigm: a method to study sexual motivation and performance of female rats. Brain Res Prot. 1999; 3(3): 320-25. [DOI:10.1016/S1385299X(98)00057-9]

19. Willoughby KN, Sarkar AJ, Boyadjieva NI, Sarkar DK. Neonatally administered tert-octylphenol affects onset of puberty and reproductive development in female rats. $\begin{array}{lll}\text { Endocrine. } & 2005 ; & 26(2):\end{array}$ [DOI:10.1385/ENDO:26:2:161]

20. Faber KA, Hughes CL .The effect of neonatel exposure to diethylstiblbestrol genistein and zearalenone on pituitary responsiveness and sexually dim orphic nucleus volume in the castrated adult rat. Biol Reprod. 1991; 45(4): 649-53. [DOI:10.1095/biolreprod45.4.649] [PMID]

21. Parandin R, Behnam-Rassouli M, Mahdavi-Shahri N. Oestrogenic action of neonatal tamoxifen on the hypothalamus and reproductive system in female mice. Reprod Fertil Dev. 2016; 29(5): 1012-20. [DOI:10.1071/RD15361] [PMID]

22. Losa-Ward SM, Todd KL, McCaffrey KA, Tsutsui K, Patisaul HB. Disrupted organization of rfamide pathways in the hypothalamus is associated with advanced puberty in female rats neonatally exposed to bisphenol A. Biol Reprod. 2012; 87(2): 28. [DOI:10.1095/biolreprod.112.100826] [PMID] [PMCID] 
23. Brill DS, Moenter SM. Androgen receptor antagonism and an insulin sensitizer block the advancement of vaginal opening by high-fat diet in mice. Biol Reprod. 2009; 81(6): 1093-8. [DOI:10.1095/biolreprod.109.079301] [PMID] [PMCID]

24. Sisk CL, Foster DL. The neural basis of puberty and adolescence. Nat Neurosci. 2004; 10: 1040-47. [DOI:10.1038/nn1326] [PMID]

25. Andrews WW, Advis JP, Ojeda SR. The maturation of estradiol-negative feedback in female rats: evidence that the resetting of the hypothalamic "gonadostat" does not precede the first preovulatory surge of gonadotropins. Endocrinology. 1981; 109(6): 2022-31. [DOI:10.1210/endo-109-6-2022] [PMID]

26. Honma S, Suzuki A, Buchanan DL, Katsu Y, Watanabe H, Iguchi Y. Low dose effect of in utero exposure to bisphenol A and diethylstilbestrol on female mouse reproduction. Reprod Toxicol. 2002; 16(2): 117-22. [DOI:10.1016/S08906238(02)00006-0]

27. Wiegand SJ, Terasawa E, Bridson WE, Goy RW. Effects of discrete lesions of preoptic and suprachiasmatic structures in the female rat. Alterations in the feedback regulation of gonadotropin secretion. Neuroendocrinol. 1980; 31(2): 14757. [DOI:10.1159/000123066] [PMID]

28. May PC, Kohama SG, Finch CE. N-methyl-aspartic acid lesions of the arcuate nucleus in adult C57BL/6J mice: a new model for age-related lengthening of the estrous cycle. Neuroendocrinol. 1989; 50(5): 605-12. [DOI:10.1159/000125288] [PMID]

29. Terasawa E, Fernandez DL. Neurobiological mechanisms of the onset of puberty in primates. Endocr Rev. 2001; 22(1): 111-51. [DOI:10.1210/er.22.1.111] [PMID]

30. Tsukahara S. Sex differences and the roles of sex steroids in apoptosis of sexually dimorphic nuclei of the preoptic area in postnatal rats. J Neuroendocrinol. 2009; 21(4): 370-76. [DOI:10.1111/j.1365-2826.2009.01855.x] [PMID]
31. Mc Carthy MM. Estradiol and the developing brain. Physiol Rev. 2008; $28(1)$ : 91-124. [DOI:10.1152/physrev.00010.2007] [PMID] [PMCID]

32. Ksheerasagar RL, Kaliwal BB. Effects of carbosulfan administration schedules on estrous cycle and follicular dynamics in albino mice. Ind Health. 2008; 46(3): 210-16. doi:10.2486/indhealth.46.210 [DOI:10.2486/indhealth.46.210] [PMID]

33. Ogbuehi IH, Ebong OO, Obianime AW. A preliminary study on the effect of Abrus precatorius Linn on Reproductive Parameters in Female Rattus norvegicus, wistar strain. European J Med Plants. 2015; 7: 156-166. [DOI:10.9734/EJMP/2015/15271]

34. Nakagawa Y, Suzuki T. Cytotoxic and xenoestrogenic effects via biotransformation of trans-anethole on isolated rat hepatocytes and cultured MCF-7 human breast cancer cells. Biochem Pharmacol. 2003; 66(1): 63-73. [DOI:10.1016/S0006-2952(03)00208-9]

35. Nagel SC, vom Saal FS, Thayer KA, Dhar MG, Boechler M, Welshons WV. Relative binding affinity-serum modified access (RBA-SMA) assay predicts the relative in vivo bioactivity of the xenoestrogens bisphenol A and octylphenol. Environ Heath Perspect. 1997; 105(1): 70-6. [DOI:10.1289/ehp.9710570] [PMID] [PMCID]

36. Vom Saal FS, Cooke PS, Buchanan DL, et al. A physiologically based approach to the study of bisphenol A and other estrogenic chemicals on the size of reproductive organs, daily sperm production, and behavior. Toxicol Ind $\begin{array}{lll}\text { Health. } & 1998 ; & \text { 14(1-2): }\end{array}$ [DOI:10.1177/074823379801400115] [PMID]

37. Gaido KW, Leonard LS, Lovell S, et al. Evaluation of chemicals with endocrine modulating activity in a yeast-based steroid hormone receptor gene transcription assay. Toxicol Appl Pharmacol. 1997; 143(1): 205-12. [DOI:10.1006/taap.1996.8069] [PMID]

\section{How to Cite This Article:}

Parandin R, Yousofvand N. Foeniculum vulgare (Fennel) Effects on Puberty Timing, Reproductive Function and Behaviour in Adult Female Mice Following Neonatal Exposure. J Adv Med Biomed Res. 2019; 27 (121) :16-22

\section{Download citation:}

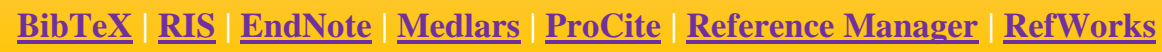

\section{Send citation to:}

(3) Mendeley 2 Zotero (i) RefWorks $\underline{\text { RefWorks }}$ 